\title{
A Comparative Study of Perioperative and Survival Outcomes of Robot-Assisted Radical Cystectomy in Patients Over 80 and Under 80 Years Old
}

\section{Shangxun Xie}

Nanjing University Medical School

\section{Zihan Zhao}

Nanjing University Medical School

\section{Baofu Feng}

Nanjing Drum Tower Hospital: Nanjing University Medical School Affiliated Nanjing Drum Tower Hospital

\section{Shiwei Zhang}

Nanjing Drum Tower Hospital: Nanjing University Medical School Affiliated Nanjing Drum Tower Hospital

\section{Gutian Zhang}

Nanjing Drum Tower Hospital: Nanjing University Medical School Affiliated Nanjing Drum Tower Hospital

\section{Xiaogong Li}

Nanjing Drum Tower Hospital: Nanjing University Medical School Affiliated Nanjing Drum Tower Hospital

\section{Hongqian Guo}

Nanjing Drum Tower Hospital: Nanjing University Medical School Affiliated Nanjing Drum Tower Hospital

\section{Yang Rong ( $\nabla$ doctoryr@gmail.com )}

Nanjing Drum Tower Hospital: Nanjing University Medical School Affiliated Nanjing Drum Tower Hospital

\section{Research}

Keywords: robotic surgical procedures, radical cystectomy, bladder cancer, octogenarians

Posted Date: February 5th, 2021

DOI: https://doi.org/10.21203/rs.3.rs-173887/v1 
License: (c) (i) This work is licensed under a Creative Commons Attribution 4.0 International License. Read Full License

Version of Record: A version of this preprint was published at World Journal of Surgical Oncology on July 6th, 2021. See the published version at https://doi.org/10.1186/s12957-021-02312-4. 


\section{Abstract}

Background: Radical cystectomy (RC) is the standard treatment for bladder cancer, but the safety and efficacy of this treatment for elderly people need to be considered. We compare perioperative data and survival outcomes between elderly ( $\geq 80$ years) and younger ( $₫ 80$ years) patients undergoing robotassisted radical cystectomy (RARC).

Methods: We reviewed demographic, perioperative clinical and follow-up data of 190 consecutive patients with urothelial carcinoma of bladder who received RARC from M ay 2015 to December 2018 in Nanjing Drum Tower Hospital. The patients were divided into 2 groups by age: $\geq 80$ years and $₫ 80$ years. Perioperative outcomes were compared between 2 groups. Logistic regression method was used to analyze the factors that may affect preoperative complications. Cox regression model was employed to analyze the factors affecting 3-year overall survival (OS), recurrence-free survival (RFS), and cancerspecific survival (CSS).

Results: Of the 190 patients, 44 (23.2\%) were octogenarians. The elderly patients did not statistically differ from younger patients in most of the demographic, perioperative and pathological information. American Society of Anesthesiologists (ASA) score $(\mathrm{p}=0.045)$ and Charlson comorbidity index (CCl) $(p=0.035)$ could predicted high-grade and any grade complications, respectively. Positive lymph node and pT $\geq 3$ were main factors affecting OS, RFS and CSS. ASA score $(p=0.048)$ and $\mathrm{CCl}(\mathrm{p}=0.003)$ could predicted OS and RFS, respectively. Elderly group had worse OS $(p=0.007)$ and CSS $(p=0.027)$ but similar RFS $(p=0.147)$ compared with younger group.

Conclusion: The elderly who received RARC had similar risk of perioperative complications and RFS compared with younger patients. RARC could be an alternative treatment for select octogenarians.

\section{Introduction}

Bladder cancer (BCa) is the second most common urinary tract malignancy. In 2018, there were 549, 393 new cases and 199, 922 deaths of bladder cancer around the world[1]. The incidence of bladder cancer increases with age, and about 46\% of patients diagnosed with bladder cancer from 2013 to 2017 in US were 80 years or older[2]. With the aggravating trend of aging population throughout the world, we could predict that the number of elderly patients with bladder cancer will be further increasing in the future.

Radical cystectomy (RC) and pelvic lymph node dissection is still the standard of care for the treatment of localized muscle invasive bladder cancer (MIBC) and high risk non-muscle invasive tumor (NMIBC)[3]. However, not all patients are suitable for RC due to high morbidity rate and age has been once a key factor to consider whether to take the operation. Although current guidelines for treatment of MIBC do not exclude the possibility of RC for old patients, they suggest that life expectancy should still be taken into account[4]. More minimally invasive approaches are underscored to reduce the surgical risk of RC in elderly patients. 
Robot-assisted radical cystectomy (RARC) has been proved to have great advantages in decreased intraoperative blood loss, decreased blood transfusion rate and shorter hospital stay compared with other approaches. In addition, RARC improves the visualization and ergonomics of surgery for urologists $[5,6]$. Nevertheless, the data about the outcomes of RARC in octogenarians is limited. It is still controversial whether it is safe and feasible for the elderly over 80 years old to receive RARC according to previous researches $[7,8]$.

In view of this, the aim of our study is to report the perioperative and short-term oncological outcomes of RARC in elderly BCa patients, and to compare these data with the outcomes observed in younger patients.

\section{Methods}

\section{Clinical data}

From May 2015 to December 2018, a total of 203 consecutive patients who underwent RARC at Nanjing Drum Tower Hospital. Patients with missing information or lack of follow-up were excluded $(n=13)$. Therefore, 190 patients were reviewed and divided into 2 groups according to the age, those who were 80 years old or older $(n=44)$, and those below $80(n=146)$, for comparison.

Main indications for RARC were muscle invasive urothelial carcinoma and high-risk non-muscle invasive urothelial carcinoma. All pathological specimens were examined by the experienced pathologists of Nanjing Drum Tower Hospital. The tumor grade and classification was in accordance with 2016 WHO (World Health Organization) classification standard[9]. The pathological staging was in accordance with 8th edition TNM staging method of American Joint Committee on cancer (AJCC) in 2017[10].All 90-days postoperative complications were defined and recorded on the basic of an established five-grade of the Clavien-Dindo system. Minor complications were classified as grades 1 and 2, while major complications were classified as grades 3,4 , and 5[11].

\section{Surgery}

All patients received RARC and urinary diversion with or without pelvic lymphadenectomy by da-Vinci Si (Intuitive Surgical, Sunnydale, CA) robot. And patients received three different options for urinary diversion, including ileal conduit, orthotopic neobladder, or ureterostomy.

\section{Follow-up}

The patients were followed up every 3 months for the first year, every 6 months for the second year, and once a year thereafter. Follow-up included physical examination, blood routine examination, liver and kidney function, electrolyte, chest CT, contrast enhanced CT examination of urinary system (according to the patient's renal function). 


\section{Statistical analysis}

The Mann-Whitney test was used to assess differences in continuous variable between two groups. Differences in categoric variables between the two groups were assessed with chi-square test. Recurrence-free survival (RFS) was defined as time from date of RARC to local recurrence or distant metastasis, based on pathological or radiologic evidence. Overall survival (OS) was defined as time from date of RARC to death due to any reasons. Cancer-specific survival (CSS) was defined as time from date of RARC to death due to bladder cancer. Factors that may affect the prognosis of RARC (age, sex, lymph node dissection, American Society of Anesthesiologists (ASA) score, Charlson comorbidity index (CCI), T stage, lymph node metastasis) were included in Cox multivariate risk proportion model to analyze their impact on OS, RFS and CSS. Univariable and multivariable logistic regression models were used to analyze the association of complications with risk factors of interest, and assessed the impact of age ( $\geq 80$ vs $<80$ ) on the risk of intraoperative blood loss, length of stay, high-grade and any grade complications. All regression data were summarized by hazard ratios (HR) with $95 \%$ confidence intervals (Cls). The values of $p<0.05$ were regarded as statistical significance. Because the predictive nature of each factor in the presence of other factors was of interest, all variables were included in the multivariable analysis without considering the univariable results. The distributions of OS, RFS and CSS stratified by age ( $\geq 80$ vs $<80$ ) were described using Kaplan-Meier curve and compared using log-rank test. All analyses were performed with the SPSS version 25.0 (IBM Corp.).

\section{Results}

\section{Patient and perioperative characteristics}

The series included 146 patients $<80$ years and 44 patients $\geq 80$ years (Table 1 ). The preoperative parameters (sex, BMI, ASA score, $\mathrm{CCl}$ ) were similar in younger and elderly groups. However, in terms of perioperative outcomes, mean operating time was significantly shorter in octogenarians $(p<0.001)$. Transfusions were more commonly given to elderly group $(p=0.015)$, while the pelvic lymph node dissection (PLND) were less performed in this group $(p=0.019)$. In addition, no differences were noted between groups in respect of urinary diversion, pathological results, length of stay, complications at all grades and 90-days postoperative mortality.

\section{Complication and survival analyses}

The logistic regression analysis of complications showed that ASA score $(H R=4.662 ; p=0.045)$ could independently predict occurrence of major complications and $\mathrm{CCI}(\mathrm{HR}=1.608 ; p=0.035)$ was significant predictor of any-grade complications, but other variables were not independent predictors (Table 2). Meanwhile, We also inspected the impact of age on the risk of increased blood loss, transfusion, prolonged hospitalization, major and any grade complications (Table 3 ). The risk of above factors were not increased in the octogenarians. 
Median follow-up time of all patients was 29.1 months (range from 7 to 58 months). Kaplan-Meier curves showed that 3 -year RFS were $72.3 \%$ and $54.4 \%$ in younger and elderly groups $(p=0.147)$, respectively. In addition, 3-year CSS and OS of octogenarians was also significantly lower than that of younger group (Figure 1). In Cox multivariable regression analyses(Table 4), $\mathrm{CCl}(\mathrm{HR}=1.812 ; p=0.003)$, tumor stage $\mathrm{pT} \geq 3(\mathrm{HR}=3.206 ; p \otimes 0.001)$ and positive lymph node status $(\mathrm{pN}(+))(\mathrm{HR}=3.615 ; p \rrbracket 0.001)$ were independent predictors of RFS. Similarly, $\mathrm{pT} \geq 3(\mathrm{HR}=5.369 ; p \rrbracket 0.001)$ and $\mathrm{pN}(+)(\mathrm{HR}=3.779 ; p \square$ $0.001)$ could predicted CSS, while ASA scores ( $\mathrm{HR}=2.076 ; p=0.048), \mathrm{pT} \geq 3(\mathrm{HR}=4.553 ; p \otimes 0.001)$ and

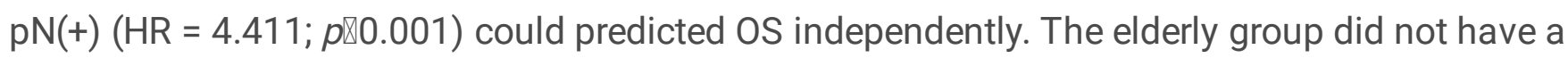
significant higher risk of lower RFS (HR $=1.096 ; p=0.806)$ and CSS $(H R=1.455 ; p=0.337)$ compared with younger group after RARC.

\section{Discussion}

The treatment of bladder cancer in elderly patients is still a controversial issue for urologists. Although many reports recommended RC as a therapeutic option for octogenarians[12,7,13]. More potential anesthesia risks, more comorbid conditions and shortened life expectancy in elderly patients often drive physicians and patients away from cystectomy[14-16].

With the development of minimally invasive surgery, especially robot-assisted surgery, the perioperative outcomes, including estimated blood loss(EBL), blood transfusion rates and rehabilitation, have been improved without sacrificing the oncologic results[6,17]. In our cohort, the whole cohort also had a lower EBL than that in the previous open RC cohort[17]. Those suggest that RARC may bring better benefits to the elderly in the respect of intraoperative damage control and enhance the safety of operation relatively. Furthermore, compared with younger group, Groote et al. found that elderly group had similar EBL and significantly shorter operative time[12]. Our study found similar results, but we also suggested that the elderly group had higher blood transfusion rate. It may attribute to the lower preoperative hemoglobin in the elderly group than in the younger group ( $119 \mathrm{vs} 126 \mathrm{~g} / \mathrm{L}, p=0.015)$. And the concerns about elderly patient frailty and relatively poor compensatory ability after blood loss may lead anesthesiologists to relax blood transfusion indications during operation[18]. Meanwhile, that surgeons tended to operate faster to reduce anesthetic risks in elderly patients, so ileal conduit and lymphadenectomy was less performed in the elderly group than in the younger group.

$\mathrm{RC}$ and urinary diversion present challenges of complications to all the patients, especially to the elderly. A comparative study of RC with different approaches for patients over 75 years suggested that there were no significant differences in surgical morbidity or 90-day readmission rates between the RARC and open RC groups, but RARC was correlated with a shorter hospital stay[19]. In our cohort, the incidence of postoperative complications in elderly patients was lower than that in the previous open RC cohort of elderly patients[20]. Those may indicate that RARC has relative advantages over open RC in terms of postoperative rehabilitation of elderly patients. Moreover, in terms of distribution of complications in different grades or 90-day mortality, Groote et al. showed that there was no significant difference between the elderly and young group, but they did not analyze the influencing factors of complications[12]. Our 
research has come to a similar conclusion, and further analysis showed that ASA score and CCI, rather than age, could predict major and any grade complications respectively. Previous RARC cohort also showed that high ASA score was independent predictor of major complications[21]. Therefore, the incidence of complications after RARC is mainly related to the basic physical condition of the patients, but not to the age.

With regard to survival outcomes, Groote et al. has shown that elderly patients had a similar 3-year RFS but worse CSS compared with young patients, and pathological stage was still the main predictors of survival outcomes[12]. In our study, the octogenarians also had a similar 3-year RFS (Figure.1), and tumor stage and positive lymph node, rather than age, were significant predictors of oncologic outcomes. However, OS and CSS were significantly higher in elderly. Relatively higher tumor stage, less use of PLND, and physical condition may result in poor OS and CSS for the elderly. Firstly, we have already pointed out that high tumor stage was associated with survival outcomes. Secondly, Chamie et al. suggested that the survival benefit of RC in the elderly is mainly acquired by the use of PLND[22]. Although the PLND ratio of the elderly patients in our study (75\%) was higher than that of the previous elderly cohorts (32\%)[12,23], it was still lower than that of the younger patients $(89 \%)$. This may be due to multidisciplinary discussions among urologists and anesthesiologists, as well as concerns about postoperative complications. Lastly, the impacts of ASA score and $\mathrm{CCl}$, which can reflect the physical condition of the elderly, on long-term survival outcome are still controversial. Previous study has suggested that $\mathrm{CCl}$ is an independent predictor of OS[24], but other study has shown that neither CCI nor ASA could was predictor of 5-year competing (non-bladder cancer) mortality[25]. In our cohort, Cox multivariable regression analysis show that ASA score and $\mathrm{CCI}$ can independently predict OS and RFS, respectively. The differences in the accuracy of cancer information record, follow-up time and sample size may be the explanation for these different findings[24]. To summarize, age should not be the only consideration for the elderly patients with bladder cancer. Preoperative comprehensive assessment is very important for the operation of elderly patients.

This study possessed several limitations. Firstly, our study was a retrospective study in which the survival data were acquired through follow-up, thus we may not be able to obtain information such as the exact time of recurrence and death of the patient. Moreover, including more elderly patients and prolonging the follow-up time will have more persuasion. Finally, selection bias for RARC may also have influenced our results, which make it possible for only elderly patients with relatively good health condition to underwent RARC.

\section{Conclusion}

Based on the outcomes of our comparative study, elderly patients who received RARC doesn't show increase perioperative risks compared with younger patients. Only $T$ stage and lymph node status, and not age, were able to predict oncologic outcomes. In addition, ASA score and CCI also have certain value in predicting postoperative complications and short-term survival outcome. Meanwhile, statistically lower 
OS and CSS remind us to carefully choose candidates for RARC in elderly patients. All in all, RARC can be used as one of the treatment options for bladder cancer in the elderly.

\section{Abbreviations}

RC: Radical cystectomy; RARC: robot-assisted radical cystectomy; OS: overall survival; RFS: recurrencefree survival; CSS: cancer-specific survival; ASA: American Society of Anesthesiologists; CCI: Charlson comorbidity index;; MIBC: muscle invasive bladder cancer; WHO: World Health Organization; AJCC: American Joint Committee on cancer; HR: Hazard Risk; Cls: confidence intervals; PLND: pelvic lymph node dissection; EBL: estimated blood loss; LVI: Iymphovascular invasion

\section{Declarations}

\section{Acknowledgements}

We are grateful to all the patients and doctors contributed to this paper.

\section{Disclosure}

There are no conflicts of interest.

\section{Authors' contributions}

Rong Yang and Hongqian Guo were responsible for the conception of the work. Shangxun Xie and Zihan Zhao wrote the manuscript. Baofu Feng and Shiwei Zhang made the tables and figures. Gutian Zhang and Xiaogong Li were responsible for retrieving the medical record of the enrolled patients. All authors finally approved the manuscript version to be published.

\section{Funding}

This research has received research grants from National Natural Science Foundation of China (81772727, 81972388, 81772710) and Nanjing Health Science and Technology Development Fund (ZKX19011).

\section{Availability of data and materials}

The raw data of this paper are available upon reasonable request to the corresponding author.

\section{Ethics approval and consent to participate}

The study was approved by the Medical Ethics Committee for Human Experiments of Nanjing Drum Tower Hospital.

\section{Consent for publication}


We have obtained written informed consent for publication from all patients in this study.

\section{Competing interests}

The authors declare that they have no conflict of interest.

\section{References}

1. Bray F, Ferlay J, Soerjomataram I, Siegel RL, Torre LA, Jemal A (2018) Global cancer statistics 2018: GLOBOCAN estimates of incidence and mortality worldwide for 36 cancers in 185 countries. CA: a cancer journal for clinicians 68 (6):394-424. doi:10.3322/caac.21492

2. Howlader N NA, Krapcho M, Miller D, Brest A, Yu M, Ruhl J, Tatalovich Z, Mariotto A, Lewis DR, Chen HS, Feuer EJ, Cronin KA (eds) (2020) SEER Cancer Statistics Review, 1975-2017, National Cancer Institute. Bethesda, MD, https://seer.cancer.gov/csr/1975_2017/, based on November 2019 SEER data submission, posted to the SEER web site, April 2020.

3. Witjes JA, Bruins HM, Cathomas R, Compérat EM, Cowan NC, Gakis G, Hernández V, Espinós EL, Lorch A, Neuzillet Y (2020) European Association of Urology guidelines on muscle-invasive and metastatic bladder cancer: summary of the 2020 guidelines. European Urology. doi:10.1016/j.eururo.2020.03.055

4. Extermann M, Aapro M, Bernabei R, Cohen HJ, Droz J-P, Lichtman S, Mor V, Monfardini S, Repetto L, Sørbye $L$ (2005) Use of comprehensive geriatric assessment in older cancer patients::

Recommendations from the task force on CGA of the International Society of Geriatric Oncology (SIOG). Critical reviews in oncology/hematology 55 (3):241-252.

doi:10.1016/j.critrevonc.2005.06.003

5. Tyritzis SI, Collins J, Wiklund NP (2018) The current status of robot-assisted cystectomy. Indian Journal of Urology 34 (2):101-109. doi:10.4103/iju.IJU_355_17

6. Bochner BH, Dalbagni G, Marzouk KH, Sjoberg DD, Lee J, Donat SM, Coleman JA, Vickers A, Herr HW, Laudone VP (2018) Randomized trial comparing open radical cystectomy and robot-assisted laparoscopic radical cystectomy: oncologic outcomes. European urology 74 (4):465-471. doi:10.1016/j.eururo.2018.04.030

7. Phillips EA, Uberoi V, Tuerk IA (2014) Robot-assisted radical cystectomy in octogenarians. Journal of endourology 28 (2):219-223. doi:10.1089/end.2013.0159

8. Lau CS, Talug J, Williams SB, Josephson DY, Ruel NH, Chan KG, Wilson TG (2012) Robotic-assisted laparoscopic radical cystectomy in the octogenarian. The International Journal of Medical Robotics and Computer Assisted Surgery 8 (2):247-252. doi:10.1002/rcs.460

9. Humphrey PA, Moch H, Cubilla AL, Ulbright TM, Reuter VE (2016) The 2016 WHO classification of tumours of the urinary system and male genital organs-part B: prostate and bladder tumours. European urology 70 (1):106-119. doi:10.1016/j.eururo.2016.02.028 
10. AminMB E, GreeneF,etal,eds (2017) AJCC Cancer Staging Manual. 8th ed. Springer. doi:10.1007/9783-319-40618-3

11. Dindo D, Demartines N, Clavien $P$ (2004) Classification of surgical complications: a new proposal with evaluation in a cohort of 6336 patients and results of a survey. Ann Surg 240 (2):205-213. doi:10.1097/01.sla.0000133083.54934.ae

12. De Groote R, Gandaglia G, Geurts N, Goossens M, Pauwels E, D'Hondt F, Gratzke C, Fossati N, De Naeyer G, Schatteman P (2016) Robot-assisted radical cystectomy for bladder cancer in octogenarians. Journal of endourology 30 (7):792-798. doi:10.1089/end.2016.0050

13. Yanagihara Y, Nishida K, Watanabe R, Koyama K, Sawada Y, Noda T, Asai S, Fukumoto T, Miura N, Miyauchi Y (2019) Feasibility of Laparoscopic Radical Cystectomy in Elderly Patients: A Comparative Analysis of Clinical Outcomes in a Single Institution. Acta Medica Okayama 73 (5):417418. doi:10.18926/AMO/57371

14. Prout Jr GR, Wesley MN, Yancik R, Ries LA, Havlik RJ, Edwards BK (2005) Age and comorbidity impact surgical therapy in older bladder carcinoma patients: a population-based study. Cancer 104 (8):1638-1647. doi:10.1002/cncr.21354

15. Izquierdo L, Peri L, Leon P, Ramírez-Backhaus M, Manning T, Alcaraz A, Roupret M, Solsona E, Rubio J, Sengupta S (2015) The role of cystectomy in elderly patients-a multicentre analysis. BJU international 116:73-79. doi:10.1111/bju.13227

16. Shariat SF, Milowsky M, Droller MJ (2009) Bladder cancer in the elderly. Urologic Oncology Seminars \& Original Investigations 27 (6):653-667. doi:10.1016/j.urolonc.2009.07.020

17. Bochner BH, Dalbagni G, Sjoberg DD, Silberstein J, Paz GEK, Donat SM, Coleman JA, Mathew S, Vickers A, Schnorr GC (2015) Comparing open radical cystectomy and robot-assisted laparoscopic radical cystectomy: a randomized clinical trial. European urology 67 (6):1042-1050. doi:10.1016/j.eururo.2014.11.043

18. Linder BJ, Frank I, Cheville JC, Tollefson MK, Thompson RH, Tarrell RF, Thapa P, Boorjian SA (2013) The impact of perioperative blood transfusion on cancer recurrence and survival following radical cystectomy. European urology 63 (5):839-845. doi:10.1016/j.eururo.2013.01.004

19. Nguyen DP, Awamlh BAHA, Charles Osterberg E, Chrystal J, Flynn T, Lee DJ, Scherr DS (2015) Postoperative complications and short-term oncological outcomes of patients aged $\geq 80$ years undergoing robot-assisted radical cystectomy. World Journal of Urology 33 (9):1315-1321. doi:10.1007/s00345-014-1446-7

20. Donat SM, Siegrist T, Cronin A, Savage C, Milowsky MI, Herr HW (2010) Radical cystectomy in octogenarians-does morbidity outweigh the potential survival benefits? The Journal of urology 183 (6):2171-2177. doi:10.1016/j.juro.2010.02.015

21. Smith AB, Raynor M, Amling CL, Busby JE, Castle E, Davis R, Nielsen M, Thomas R, Wallen EM, Woods M (2012) Multi-institutional analysis of robotic radical cystectomy for bladder cancer: perioperative outcomes and complications in 227 patients. Journal of Laparoendoscopic \& Advanced Surgical Techniques 22 (1):17-21. doi:10.1089/lap.2011.0326 
22. Chamie K, Hu B, DeVere White RW, Ellison LM (2008) Cystectomy in the elderly: does the survival benefit in younger patients translate to the octogenarians? BJU international 102 (3):284-290. doi:10.1111/j.1464-410X.2008.07636.x

23. Zattoni F, Palumbo V, Giannarini G, Crestani A, Kungulli A, Novara G, Zattoni F, Ficarra V (2018) Perioperative outcomes and early survival in octogenarians who underwent radical cystectomy for bladder cancer. Urologia internationalis 100 (1):13-17. doi:10.1159/000478990

24. Fischer-Valuck BW, Rao YJ, Rudra S, Przybysz D, Germino E, Samson P, Baumann BC, Gay H, Michalski J (2018) Treatment patterns and overall survival outcomes of octogenarians with muscle invasive cancer of the bladder: an analysis of the national cancer database. The Journal of urology 199 (2):416-423. doi:10.1016/j.juro.2017.08.086

25. Froehner M, Koch R, Hübler M, Heberling U, Novotny V, Zastrow S, Hakenberg OW, Wirth MP (2018) Predicting 90-day and long-term mortality in octogenarians undergoing radical cystectomy. BMC urology 18 (1):91. doi:10.1186/s12894-018-0402-z

\section{Tables}

Table 1. Demographic, perioperative and pathological characteristics of 190 patients treated with robotassisted radical cystectomy (RARC) 


\begin{tabular}{|c|c|c|c|}
\hline & $\begin{array}{l}\text { Elderly group ( } \geqq 80 \text {, } \\
\mathrm{n}=44 \text { ) }\end{array}$ & $\begin{array}{l}\text { Younger group ( } ₫ 80 \text {, } \\
\mathrm{n}=146)\end{array}$ & $\begin{array}{l}\mathrm{p}- \\
\text { value }\end{array}$ \\
\hline age median (range) & $83(80-92)$ & $65(41-79)$ & $\varangle 0.001$ \\
\hline Sex (male : female) & $37: 7$ & 130:16 & 0.378 \\
\hline BMI median (range) ${ }^{1}$ & $22.9(15.4-30.4)$ & 23.5(16.5-35.5) & 0.083 \\
\hline ASA score $(1 / 2 / 3)^{2}$ & $12 / 5 / 27$ & $46 / 33 / 67$ & 0.137 \\
\hline $\operatorname{CCl} \operatorname{class}(0 / 1 / 2 / 3)^{3}$ & $9 / 19 / 11 / 5$ & $32 / 72 / 40 / 2$ & 0.053 \\
\hline $\mathrm{Hb}, \mathrm{g} / \mathrm{L}$ median (range) ${ }^{4}$ & $119(63-157)$ & $126(53-169)$ & 0.015 \\
\hline Alb, g/L median (range) ${ }^{5}$ & $36.9(31.3-59.3)$ & $37.6(24.4-47.3)$ & 0.146 \\
\hline Operating time, min median (range) & $308(160-480)$ & $399(235-670)$ & $\square 0.001$ \\
\hline EBL, ml median(range) ${ }^{6}$ & $300(100-1400)$ & $406(100-1900)$ & 0.475 \\
\hline Transfusion, n (\%) & $21(47.7)$ & $41(28.1)$ & 0.015 \\
\hline PLND, n $(\%)^{7}$ & $33(75.0)$ & $130(89.0)$ & 0.019 \\
\hline $\begin{array}{l}\text { Number of lymph node, } \mathrm{n} \text { median } \\
\text { (range) }\end{array}$ & $13(1-29)$ & $15(1-39)$ & 0.274 \\
\hline Urinary diversion, n (\%) & & & 0.051 \\
\hline ileal conduit & $25(56.8)$ & $95(65.1)$ & \\
\hline ileal neobladder & $0(0)$ & $10(6.8)$ & \\
\hline ureterostomy & 19(43.2) & $41(28.1)$ & \\
\hline cT (cT2 over) n, (\%) & $21(47.7)$ & $52(35.6)$ & 0.148 \\
\hline cT (Tis/a/1/2/3/4) & $2 / 2 / 8 / 13 / 11 / 8$ & $7 / 7 / 44 / 36 / 40 / 12$ & 0.375 \\
\hline $\mathrm{cN}(+) \mathrm{n},(\%)$ & $6(13.6)$ & $36(24.7)$ & 0.122 \\
\hline $\operatorname{LVI}(+) n,(\%)^{8}$ & $17(38.6)$ & $54(35.5)$ & 0.843 \\
\hline Positive surgical margin, $\mathrm{n}(\%)$ & $2(4.5)$ & $6(4.1)$ & 1.000 \\
\hline $\begin{array}{l}\text { Postoperative hospital stay, days } \\
\text { median (range) }\end{array}$ & $12(7-29)$ & $15(6-39)$ & 0.437 \\
\hline $\begin{array}{l}\text { Complications according to Clavien- } \\
\text { Dindo, } \mathrm{n}(\%)\end{array}$ & & & 0.605 \\
\hline 0 & $22(50.0)$ & $66(45.2)$ & \\
\hline $1-2$ & $18(40.9)$ & $71(48.6)$ & \\
\hline
\end{tabular}




\begin{tabular}{|llll|}
$3-5$ & $4(9.1)$ & $9(6.2)$ & \\
$90-$ days mortality, n (\%) & $3(6.8)$ & $3(2.1)$ & 0.275 \\
\hline
\end{tabular}

${ }^{1} \mathrm{BMI}=$ body mass index. ${ }^{2} \mathrm{ASA}=$ American Society of Anesthesiologists. ${ }^{3} \mathrm{CCl}=$ Charlson comorbidity index; ${ }^{4} \mathrm{Hb}=$ hemoglobin. ${ }^{5} \mathrm{Alb}=$ albumin. ${ }^{6} \mathrm{EBL}=$ estimated blood. ${ }^{7} \mathrm{PLND}=$ pelvic lymph node dissection. ${ }^{8} \mathrm{LVI}=$ lymphovascular invasion

Table 2. Logistic regression analysis of high-grade and any grade complications 
Univariable analysis

$\mathrm{HR}^{1} \quad 95 \% \mathrm{Cl}^{2}$
Multivariable analysis

$\mathrm{HR} \quad 95 \% \mathrm{Cl}$

$\mathrm{p}-$
value

\section{High-grade complications}

\begin{tabular}{|c|c|c|c|c|c|c|}
\hline Age $(\geqq 80$ vs $₫ 80)$ & 1.560 & $0.465-5.234$ & 0.471 & 1.648 & $0.403-6.734$ & 0.487 \\
\hline Sex (male vs female) & 0.332 & $0.096-1.147$ & 0.081 & 0.268 & $0.061-1.182$ & 0.082 \\
\hline PLND (yes vs no) & 0.682 & $0.142-3.267$ & 0.632 & 1.193 & $0.165-8.648$ & 0.861 \\
\hline 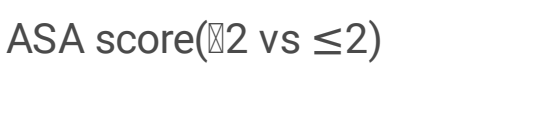 & 1.875 & $0.607-5.796$ & 0.275 & 4.662 & $\begin{array}{l}1.036- \\
20.968\end{array}$ & 0.045 \\
\hline CCI(continuous variable) & 0.754 & $0.372-1.527$ & 0.433 & 0.463 & $0.168-1.279$ & 0.138 \\
\hline 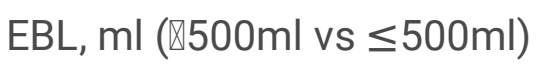 & 0.975 & $0.294-3.238$ & 0.968 & 0.672 & $0.138-3.283$ & 0.623 \\
\hline Transfusion (yes vs no) & 0.838 & $0.253-2.776$ & 0.773 & 0.936 & $0.206-4.250$ & 0.932 \\
\hline Urinary diversion & & & 0.477 & & & 0.354 \\
\hline $\begin{array}{l}\text { ileal conduit vs } \\
\text { ureterostomy }\end{array}$ & 2.043 & $0.608-6.868$ & 0.248 & 2.121 & $0.600-7.501$ & 0.243 \\
\hline ileal conduit vs neobladder & 2.472 & $\begin{array}{l}0.249- \\
24.561\end{array}$ & 0.440 & 4.881 & $\begin{array}{l}0.366- \\
65.026\end{array}$ & 0.230 \\
\hline
\end{tabular}

\section{Any grade complications}

\begin{tabular}{|c|c|c|c|c|c|c|}
\hline Age $(\geqq 80$ vs $₫ 80)$ & 0.849 & $0.437-1.652$ & 0.630 & 0.831 & $0.395-1.748$ & 0.626 \\
\hline Sex (male vs female) & 0.680 & $0.299-1.545$ & 0.357 & 1.957 & $0.804-4.764$ & 0.139 \\
\hline PLND (yes vs no) & 0.851 & $0.351-2.066$ & 0.722 & 0.953 & $0.341-2.664$ & 0.928 \\
\hline ASA score $(\llbracket 2$ vs $\leq 2)$ & 1.210 & $0.704-2.080$ & 0.490 & 0.872 & $0.438-1.737$ & 0.698 \\
\hline $\mathrm{CCl}($ continuous variable) & 1.413 & $0.998-2.000$ & 0.052 & 1.608 & $1.035-2.497$ & 0.035 \\
\hline 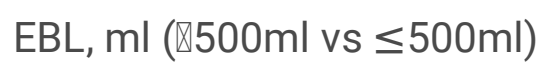 & 0.752 & $0.414-1.367$ & 0.349 & 0.706 & $0.343-1.456$ & 0.346 \\
\hline Transfusion (yes vs no) & 0.840 & $0.470-1.503$ & 0.557 & 0.831 & $0.407-1.700$ & 0.613 \\
\hline Urinary diversion & & & 0.813 & & & 0.556 \\
\hline $\begin{array}{l}\text { ileal conduit vs } \\
\text { ureterostomy }\end{array}$ & 1.081 & $0.620-1.884$ & 0.784 & 1.075 & $0.600-1.927$ & 0.807 \\
\hline ileal conduit vs neobladder & 1.533 & $0.406-5.788$ & 0.529 & 2.184 & $0.532-8.975$ & 0.279 \\
\hline
\end{tabular}

${ }^{1} \mathrm{HR}=$ Hazard Risk. ${ }^{2} \mathrm{Cl}=$ Confidence Interval. 
Table 3. Impact of age ( $\geq 80 \mathrm{vs}<80$ ) on the blood loss, transfusion, length of stay, high-grade complications, and any grade complications ${ }^{1}$

\begin{tabular}{|llll|}
\hline & HR & $95 \% \mathrm{Cl}$ & p-value \\
\hline Blood loss $>500 \mathrm{~mL}$ & 1.149 & $0.499-2.645$ & 0.744 \\
\hline Transfusion & 1.782 & $0.808-3.931$ & 0.152 \\
\hline Length of stay $>18$ days & 0.830 & $0.316-2.177$ & 0.704 \\
\hline High-grade complications & 1.791 & $0.441-7.270$ & 0.415 \\
\hline Any grade complications & 0.834 & $0.396-1.756$ & 0.632 \\
\hline
\end{tabular}

${ }^{1}$ Model adjusted for sex, ASA score, $\mathrm{CCl}$, T stage, N stage, use of PLND, and diversion technique.

Table 4. Cox proportional hazards regression analysis of overall survival, recurrence-free survival and cancer-specific survival 
Univariable analysis

Multivariable analysis

$\mathrm{HR} \quad 95 \% \mathrm{Cl}$

p- $\quad \mathrm{HR} \quad 95 \% \mathrm{Cl}$

value

p-

value

\section{overall survival}

Age $(\geqq 80$ vs $₫ 80)$

$2.564 \quad 1.465-4.489$

0.001

$1.736 \quad 0.875-3.442$

0.115

Sex male (male vs female)

$\begin{array}{lll}0.517 & 0.266-1.005 & 0.052\end{array}$

0.524

0.262-1.048

0.067

PLND (yes vs no)

0.451

0.231-0.882

0.020

0.501

$0.207-1.214$

0.126

ASA score ( $₫ 2$ vs $\leq 2)$

1.889

1.080-3.302

0.026

$2.076 \quad 1.008-4.276$

0.048

$\mathrm{CCl}$ (continuous variable)

1.523

1.108-2.093

0.009

1.113

$0.736-1.682$

0.613

$\mathrm{pT}(\geqq \mathrm{pT} 3$ vs $\unrhd \mathrm{pT} 3)$

$6.417 \quad 3.473-$

11.855

$[0.001$

4.553

2.359-8.788

00.001

$\mathrm{pN}(+\mathrm{vs}-)$

4.605

2.668-7.950

$[0.001$

4.411

$2.322-8.378$

$\square 0.001$

Positive surgical margin (+ vs

1.083

$0.337-3.478$

0.893

0.520

$0.148-1.823$

0.307

\section{recurrence-free survival}

\begin{tabular}{|c|c|c|c|c|c|c|}
\hline Age $(\geqq 80$ vs $₫ 80)$ & 1.665 & $0.921-3.011$ & 0.092 & 1.096 & $0.528-2.271$ & 0.806 \\
\hline Sex male (male vs female) & 0.724 & $0.355-1.477$ & 0.374 & 1.275 & $0.631-2.656$ & 0.515 \\
\hline PLND (yes vs no) & 0.584 & $0.286-1.195$ & 0.141 & 0.572 & $0.232-1.413$ & 0.226 \\
\hline 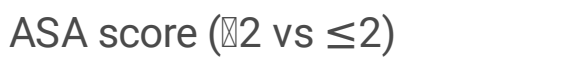 & 1.354 & $0.798-2.299$ & 0.262 & 0.931 & $0.475-1.826$ & 0.836 \\
\hline $\mathrm{CCl}$ (continuous variable) & 1.726 & $1.264-2.358$ & 0.001 & 1.812 & $1.218-2.695$ & 0.003 \\
\hline pT $(\geqq$ pT3 vs $₫$ pT3) & 4.644 & $2.665-8.094$ & {$[0.001$} & 3.206 & $1.738-5.913$ & 00.001 \\
\hline $\mathrm{pN}(+\mathrm{vs}-)$ & 4.037 & $2.359-6.908$ & {$[0.001$} & 3.615 & $1.934-6.755$ & 00.001 \\
\hline $\begin{array}{l}\text { Positive surgical margin (+ vs } \\
- \text { ) }\end{array}$ & 0.670 & $0.163-2.752$ & 0.579 & 0.292 & $0.066-1.288$ & 0.104 \\
\hline
\end{tabular}

\section{cancer-specific survival}

\begin{tabular}{|c|c|c|c|c|c|c|}
\hline Age $(\geqq 80$ vs $₫ 80)$ & 2.234 & $1.208-4.132$ & 0.010 & 1.455 & $0.676-3.132$ & 0.337 \\
\hline Sex male (male vs female) & 0.554 & $0.267-1.147$ & 0.112 & 1.690 & $0.795-3.593$ & 0.173 \\
\hline PLND (yes vs no) & 0.492 & $0.235-1.027$ & 0.059 & 0.557 & $0.211-1.476$ & 0.239 \\
\hline 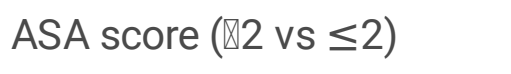 & 1.656 & $0.920-2.983$ & 0.093 & 1.598 & $0.747-3.417$ & 0.227 \\
\hline $\mathrm{CCl}$ (continuous variable) & 1.607 & $1.143-2.261$ & 0.006 & 1.328 & $0.855-2.064$ & 0.206 \\
\hline pT $(\geqq p T 3$ vs $₫ p T 3)$ & 7.471 & $\begin{array}{l}3.781- \\
14.760\end{array}$ & 00.001 & 5.369 & $\begin{array}{l}2.598- \\
11.097\end{array}$ & $\square 0.001$ \\
\hline
\end{tabular}




\begin{tabular}{|lllllll|}
\hline $\mathrm{pN}(+\mathrm{vs}-)$ & 4.364 & $2.423-7.857$ & 00.001 & 3.779 & $1.910-7.476$ & 00.001 \\
\hline $\begin{array}{l}\text { Positive surgical margin (+ vs } \\
-)\end{array}$ & 0.814 & $0.197-3.363$ & 0.776 & 0.361 & $0.080-1.636$ & 0.186 \\
\hline
\end{tabular}

\section{Figures}
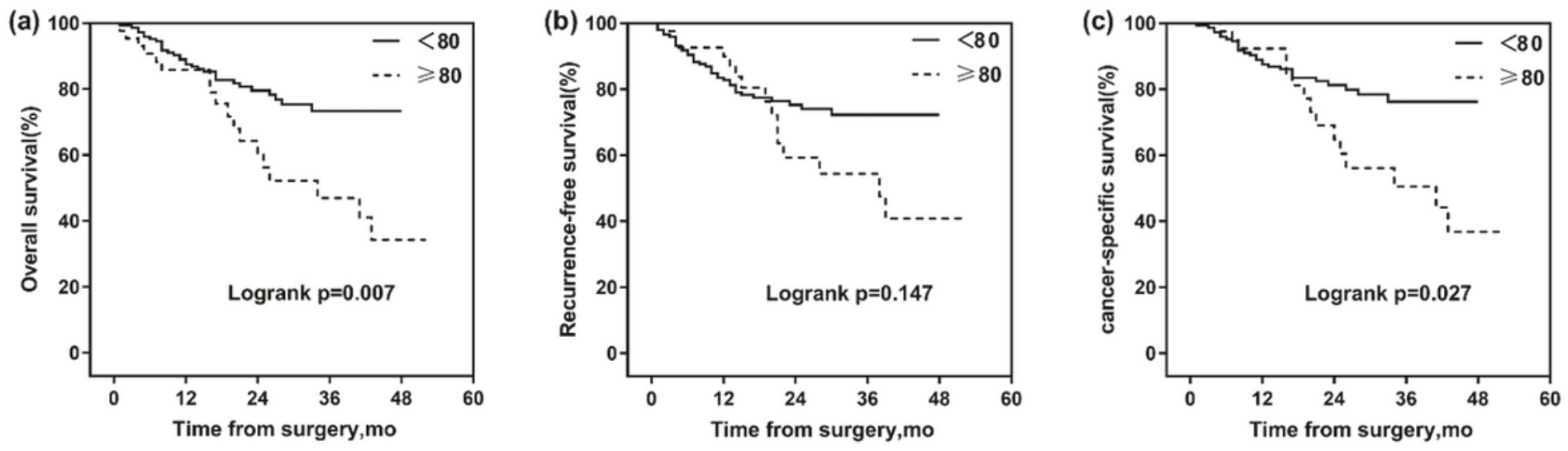

Figure 1

Kaplan-Meier curves for (a) Overall Survival and (b) Recurrence-free Survival, (c) Cancer-specific survival estimates, stratified according to age. (mo: months) 